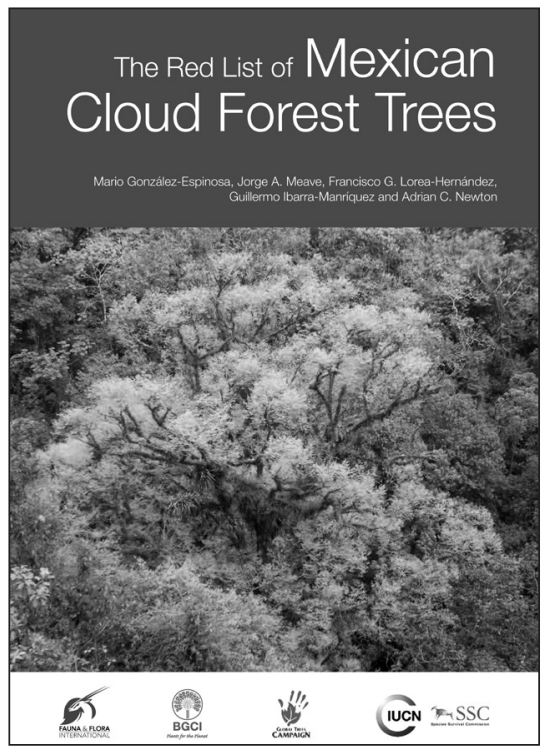

a preocupación por la conserva-

_ción de las especies silvestres y el espíritu acaparador del imperialismo europeo no parecen ser los más obvios compañeros del alma. Sin embargo, en pleno auge del Imperio Británico, en 1903, se fundó en Cambridge, Inglaterra, la organización Flora \& Fauna International, la primera con caracter internacional dedicada a la conservación de la naturaleza.

Tras su labor pionera en el sureste de África, que condujo a la creación de los parques nacionales Kruger y Serengeti, Flora \& Fauna International fue instrumental en la creación de una porción importantísima de la infraestructura organizacional mundial existente para la conservación de la naturaleza, incluyendo - por mencionar tan sólo unos ejemplos_ el World Wildlife Fund (ahora World Wide Fund for $\mathrm{Na}$ ture, WWF), la Unión Internacional para la Conservación de la Naturaleza (IUCN, siglas en inglés), la Convención sobre el Comercio Internacional de Especies Amenazadas de Fauna y Flora Silvestres (CITES, siglas en in-

\title{
LA NEBLINA SE LEVANTA: LOS ÁRBOLES DEL BOSQUE MESÓFILO DE MONTAÑA DE MÉxico, CLARAMENTE AMENAZAdOS
}

\author{
Mario González-Espinosa, Jorge A. Meave, \\ Francisco G. LoREA-HERnÁNDEZ, \\ Guillermo Ibarra-ManríQuez y Adrian C. Newton (editores)
}

\section{The Red List of Mexican Cloud Forest Trees.}

Flora \& Fauna International, Cambridge, R.U. 149 pp. 2011. ISBN: 9781903703281

glés) y, desde hace más de cuatro décadas, la elaboración y publicación de The Red Lists — las Listas Rojas de las Especies Amenazadas del mundo-.

The Red List of Mexican Cloud Forest Trees es la séptima publicación desarrollada bajo los auspicios del Grupo Global de Especialistas en Árboles, de la Comisión para la Supervivencia de las Especies de la IUCN (expresado más económicamente en inglés como IUCN/SSC Global Tree Specialist Group), que se estableció en 2003 y cuyo objetivo último es evaluar el estado de amenaza de todos los árboles del mundo. Con un objetivo tan ambicioso, no es de sorprender la priorización actual de este esfuerzo hacia la evaluación de "Los Árboles en la Cima del Mundo" (Trees at the Top of the World), aquéllas especies de los hábitats de mayor altitud, que son las más expuestas a los impactos del cambio climático global.

Así es que en la primavera de 2007, el Dr. Adrian Newton, Profesor en Ecología de la Conservación de la Universidad de Bournemouth,
Inglaterra, y Vice-Chair y Punto Focal de la Autoridad de la Lista Roja del IUCN/SSC Global Tree Specialist Group, convocó al primero de una serie de talleres y reuniones mediante los cuales diversos investigadores y especialistas de la comunidad botánica de México pudieron colaborar para desarrollar, en el transcurso de más de cuatro años, este libro magnífico. Más allá de su relevancia indiscutible para la comunidad botánica y académica, este libro es de suma utilidad para la toma de decisiones relativas a la conservación, el desarrollo sustentable y la restauración de los insólitamente bellos — pero amenazados- bosques mesófilos de montaña de México.

El contenido del libro está dividido en diez secciones, de las cuales cuatro contienen la información medular de la obra: la introducción, la lista de asesores, la Lista Roja como tal, y la lista de aquéllas especies clasificadas como de preocupación menor (Least Concern), de acuerdo con los criterios de la IUCN. Esta última sección aparece desglosada, con el perfil completo de 
cada especie, en la versión publicada del libro disponible en México y en la versión en PDF disponible en el sitio en internet de globaltrees.org.

En la introducción del libro se informa el lector sobre el proceso de elaboración de la Lista Roja de las especies arbóreas del bosque mesófilo de montaña de México. Se comienza con los criterios empleados para definir este tipo de vegetación para los propósitos de este trabajo; o quizás más bien para "acotar" entre lo que se considera bosque mesófilo de montaña y lo que no, dada la dificultad perenne que enfrentamos todos los que hemos intentado encontrar una definición sensu stricto que abarque la gran diversidad de comunidades bióticas que deben incluirse (o no, dependiendo del autor) bajo este término.

A continuación se esbozan los factores naturales y antropogénicos que representan amenazas para la existencia futura de los ecosistemas de bosque mesófilo de montaña y a sus especies, tanto en México como en el mundo. En México, su relativa rareza natural, cubriendo una porción mínima del territorio nacional, distribuido en parches aislados y frecuentemente incluyendo cuantiosas especies endémicas y/o de distribución restringida, le confiere cierta vulnerabilidad, aun sin las diversas presiones directas e indirectas que las actividades humanas ejercen, mismas que provocan que esta vulnerabilidad se transforme en una amenaza seria. La posibilidad de que esta amenaza se traduzca directamente en otras, que a su vez puedan afectar a las comunidades humanas que se benefician de los numerosos servicios ambientales brindados por los bosques mesófilos, es debidamente mencionada por los autores.

En seguida se aborda el tema interesante -y medular, para los propósitos de este libro- de la riqueza florística de los bosques mesófilos de México. Nunca deja de asombrar que estos ecosistemas sean el hábitat para una flora (y una fauna) tan excepcio- nal, no sólo en su diversidad de especies, sino también en su diversidad de familias botánicas, endemismos (entre 30-35\% de todas las plantas endémicas del país se encuentran en estos bosques) y -ipor qué no hacer hincapié en ella, ya que para quienes estos bosques son su "mero mole", es un factor primordial?- su extraordinaria belleza. Se presenta una breve recopilación de los resultados de algunos trabajos sobre la flora de los bosques mesófilos de montaña de México, los cuales, junto con otras publicaciones, proporcionan el cimiento bibliográfico del contenido de este libro. No debería sorprenderle al lector que la vasta mayoría de estas referencias hayan sido publicadas en los últimos 15 años, dado el interés y los esfuerzos sistemáticos relativamente recientes, de parte de la comunidad botánica y científica, por explorar y estudiar estos ecosistemas —además de su acceso difícil, por cuestiones tanto de topografía como de falta de vialidades y sobra de narcotraficantes, dependiendo de la región-.

A continuación se señalan las zonas principales de distribución del bosque mesófilo en el país y se mencionan algunas de las amenazas más serias que actualmente ponen en riesgo la conservación a largo plazo de estos ecosistemas. De allí se desprende la utilidad mayor de este libro: más allá de constituir un compendio de las especies de árboles de bosque mesófilo de montaña de México y el grado de amenaza que se cierne sobre cada una de ellas - utilísimo como un fin en sí mismo-, la obra realmente constituye una herramienta para los tomadores de decisiones, sean propietarios, agencias de cualquiera de los tres órdenes de gobierno, instituciones académicas o científicas, u organizaciones civiles, cuyas acciones redundan potencialmente en la conservación, alteración o destrucción de estos bosques, sus especies y servicios ambientales. Los autores hacen el énfasis debido en este punto.

El resto de la introducción - de hecho, la mayor parte de ella- se dedica a explicar cómo se compiló la lista de árboles plasmada en este libro. Se mencionan los avances medulares de los talleres y las reuniones de trabajo, así como ciertos criterios empleados: geográficos, ecológicos, morfológicos (la definición de "árbol") y sucesionales (se incluyen esencialmente especies de la vegetación primaria, pero también se incluyen -y acertadamente, considero- algunas especies secundarias que podrían ser indicadores de los efectos del cambio climático). Se describen también las fuentes consultadas para la información taxonómica y ecológica de cada especie, haciendo énfasis en los recursos humanos, expertos en sus respectivos campos o taxa botánicos. El uso de fuentes bibliográficas complementarias permitió completar otros detalles. Cabe mencionar aquí que los criterios previamente establecidos para la categorización de las especies por parte de la IUCN se incluyen en el Anexo del libro.

Muchos lectores podrían considerar que es una lástima que los editores hayan decidido no incluir mapas de distribución de cada especie. A mí en lo personal me hubiera gustado mucho ver su inclusión. La razón esgrimida para omitir estos mapas es que las fuentes de información disponibles (etiquetas de ejemplares herborizados e inventarios florísticos - no se mencionaron los bancos de datos computarizados-) se encuentran aún bajo procesos de verificación taxonómica y geográfica. No se puede discutir la validez del punto, pero dado que en los comentarios finales de la introducción se recalca la incertidumbre relativa a la información presentada, debido a la naturaleza subjetiva de adscribir valores de juicio acerca de criterios específicos que deben ejercerse sobre la base de un conocimiento incompleto de la flora y la taxonomía de los bosques mesófilos de montaña, considero que 
se podría haber extendido el implícito "y sin embargo...", a los mapas de distribución, por inexactos y provisionales que pudieran haber sido. ¿Quizás para la segunda edición?

Junto con los comentarios de conclusión se incluye también una síntesis numérica de la información presentada en las listas recopiladas (la de las especies bajo algún grado de amenaza y su contraparte, la lista de especies de preocupación menor, es decir, no amenazadas). La incluyo aquí por su gran interés y relevancia (Cuadro 1). De un total de 762 especies de árboles (distribuidos en 85 familias botánicas) de los bosques mesófilos de montaña de México, la vasta mayoría, 71\%, son especies bajo alguna categoría de amenaza $(60 \%)$, o cercana a ella (near threatened) (11\%). De éstas, $37.9 \%$ están en peligro (endangered) o en peligro crítico (critically endangered), y tres ya se extinguieron. Es de recalcarse que todas y cada una de estas 762 especies fueron evaluadas en un esfuerzo con pocos antecedentes en México.

Ante un trabajo como éste, se antoja hacer comparaciones con trabajos similares, y aunque no tuve el tiempo para realizar un análisis completo ni a fondo, busqué las primeras 44 especies que aparecen en esta Lista Roja, en la Norma Oficial Mexicana que enlista las especies consideradas en

Cuadro 1. Síntesis numérica de los resultados de la obra.

\begin{tabular}{lrl}
\hline Estatus de conservación & \multicolumn{2}{c}{$\begin{array}{c}\text { Número de } \\
\text { especies } \mathbf{( \% )}\end{array}$} \\
\hline Extintas en Estado Silvestre & 3 & $(0.4)$ \\
En Peligro Crítico & 83 & $(10.9)$ \\
En Peligro & 206 & $(27.0)$ \\
Vulnerable & 175 & $(23.0)$ \\
Casi Amenazada & 78 & $(10.2)$ \\
Datos Insuficientes & 2 & $(0.3)$ \\
Preocupación Menor & 215 & $(28.3)$ \\
No Evaluada & 0 & $(0)$ \\
\hline
\end{tabular}

categoría de riesgo por las autoridades ambientales federales, la NOM059-SEMARNAT-2010. De estas 44 especies, sólo tres también aparecen en la NOM, y siempre en categorías de riesgo por debajo de aquéllas de la Lista Roja. Desde luego, reconozco que las categorías, los criterios y las metodologías son distintas entre ambos esfuerzos, pero no deja de suscitar una preocupación acerca de la confiabilidad de la NOM, sobre todo cuando algunas especies consideradas en la Lista Roja como en peligro crítico, aparecen en la categoría más baja ("Protección Especial") de la NOM (p.ej., Vallesia spectabilis). Si bien ésta no es la ocasión para un análisis crítico de la NOM, es válido recalcar cómo los esfuerzos como esta Lista Roja nos puede inspirar para fortalecer el andamiaje legal nacional en pro de la conservación, y hasta ayudar con ello, empezando simplemente con iluminar algunas de sus desperfectos y omisiones.

La lista de asesores incluye 23 expertos, la mayoría de renombre, pero como siempre en este tipo de esfuerzo se puede pensar en aquéllos expertos cuyos nombres no aparecen y quienes posiblemente pudieron haber aportado datos y conocimientos cuya inclusión podría haber modificado, en algún grado, la información presentada en el libro. Es de suponer que algunas personas simplemente no estuvieron disponibles en los momentos oportunos, como pasa en casi todos los esfuerzos de este tipo.

La Lista Roja como tal, junto con la lista de especies de preocupación menor, resulta ser un inventario de facto de los árboles del bosque mesófilo de montaña de México. Tan sólo por esta contribución valiosa a la ciencia y la comunidad botánicas del país, el libro es digno de consultar. Pero la calidad de la información adicional sobre cada especie incluida, sobre su estatura, hábitat (dosel, subdosel, vegetación primaria o secundaria, etc.), distribución geográfica y altitudinal, endemicidad, rareza relativa, etc., lo convierte en un compendio de información florística y ecológica invaluable.

A la mitad de la lista de las especies amenazadas, se incluyen ocho páginas con 25 fotografías a color, las cuales, juntas con las dos fotografías de la portada, dan un sabor de cómo son los bosques mesófilos y su flora arbórea. Las fotografías son muy buenas, nítidas, ilustrativas y didácticas. Qué bueno hubiera sido tener una para cada especie incluida en el libro - aunque se sobrentiende que esto habría aumentado por mucho los costos de publicación de la versión impresa- . No obstante, algunas fotografías adicionales, quizás de las especies en mayor peligro, habría contribuido a aumentar aún más el valor utilitario y estético de esta obra.

No obstante el comentario anterior, los datos arriba mencionados, junto con la información medular, la que dé la razón de ser de esta Lista Roja —el grado de amenaza adscrita a cada una de las especies en ella-, hace de este libro una referencia obligada para cada investigador y botánico que desee contribuir a la conservación, aprovechamiento sustentable $\mathrm{y}$, con apremiante necesidad, la restauración de nuestros magníficos bosques mesófilos de montaña, y una herramienta indispensable para los tomadores de decisiones, que tienen en sus manos, literalmente, el poder de conservar o de extinguir estos ecosistemas y sus especies.
Antony Challenger
Asesor,
Subsecretaría de Planeación y
Política Ambiental,
Secretaría de Medio Ambiente
y Recursos Naturales (SEMARNAT),
México, D.F., México
achallenger@semarnat.gob.mx 